\title{
Design e desenvolvimento de um game assistivo para autistas
}

\author{
Filomena Maria Gonçalves da Silva Cordeiro Moita ${ }^{1}$, Lucas Henrique Viana ${ }^{2}$, \\ Felipe Miranda Medeiros ${ }^{3}$, Vilma Mussilene de Araújo Candido ${ }^{1}$ \\ ${ }^{1}$ Programa de Pós-Graduação em Ensino de Ciências e Educação Matemática - \\ Universidade Estadual da Paraíba \\ ${ }^{2}$ Departamento de Matemática - Universidade Estadual da Paraíba \\ ${ }^{3}$ Departamento de Sistemas e Computação - Universidade Federal de Campina Grande

\footnotetext{
\{filomena moita, lucas henriqk\}@hotmail.com,

felipe.miranda.mdrs@gmail.com, vmacandido@yahoo.com.br
}

\begin{abstract}
The assistive technology is increasingly present in educational contexts, however resources that helps autistic people are scarce. In this sense the current article intends to present the design, development and validation process of a assistive game, focused on the narratives building for autistic people. Called LIA, the game allows the creation of narratives dragging images to a text field, where they are formed phrases related to the selected image. The results obtained with the LIA validation, revealed that it is clear, objective and can besides stimulate ability to construct narratives, assist in the language development.
\end{abstract}

Resumo. A tecnologia assistiva está cada vez mais presente em contextos educacionais, entretanto são escassos os recursos que atendam a pessoas com necessidades especificas como os autistas. Nesse sentido, este artigo objetiva apresentar o processo de design, desenvolvimento e validação de um game assistivo, com foco na construção de narrativas para autistas. Nomeado de LIA, o game possibilita a criação de narrativas arrastando-se imagens para um campo de texto onde são formadas frases relacionadas às figuras selecionadas. Os resultados obtidos com a validação do LIA revelaram que ele é claro, objetivo e pode, além de estimular a habilidade de construção de narrativas, auxiliar no desenvolvimento da linguagem.

\section{Introdução}

O estudo e a aplicação de recursos digitais em contextos escolares é uma temática de grande importância para a sociedade e para o meio acadêmico. Destacam-se as investigações que visam aprimorar capacidades físicas, cognitivas e aprendizagem de crianças, jovens e adultos nascidos em uma era marcada pela evolução e pelo uso constante das Tecnologias Digitais da Informação e da Comunicação (TDIC).

Esse público pertence a uma geração que apresenta algumas diferenças, quando comparado com o das gerações anteriores, que não possuíam tantos equipamentos digitais em sua volta. Prensky (2001) denomina essa geração como nativos digitais, que é considerada como detentora de diferentes formas de agir, de interagir, de se comunicar e de aprender [Moita,2007]. 
São muitos os recursos, as metodologias e os relatos de experiências disponíveis nos mais variados meios de divulgação científica a respeito do uso das TDIC na escola, entretanto, ainda há uma grande lacuna no que diz respeito à usabilidade, comunicabilidade e acessibilidade desses recursos, pois muitas pessoas, como os autistas, por exemplo, têm necessidades específicas que, nem sempre, são atendidas.

Essas lacunas, inerentes ao design de muitos aplicativos ou games educacionais, podem aumentar as dificuldades ou causar efeitos indesejados no usuário, como incômodos, distrações acústicas e visuais ou aversão por seu uso. Essa situação pode ser melhorada com alguns cuidados pedagógicos que promovam, por exemplo, a produção de narrativas e métodos que facilitem a comunicação entre a interface digital e o usuário, ou seja, a interação humano-computador (IHC) [Barbosa \& Silva, 2010].

Nesse sentido, emergem os seguintes questionamentos: Como desenvolver um artefato compatível com múltiplos dispositivos e que beneficie usuários que tenham necessidades específicas, como os autistas? De que características gráficas e pedagógicas necessitaria o artefato para facilitar o processo de construção de narrativas?

Com o fim de encontrar respostas para esses questionamentos, este artigo tem o objetivo de apresentar o processo de design, desenvolvimento e validação de um game assistivo, com foco na construção de narrativas para autistas.

Nos próximos tópicos, apresentam-se alguns aspectos teóricos sobre o autismo e a habilidade da construção de narrativas, interação humano-computador e design de games, seguidos dos trabalhos relacionados. Logo após, encontra-se a metodologia, que é dividida em três subtópicos: desenvolvimento, mecânica e metodologia de aplicação do game proposto, resultados da investigação, conclusões e referências.

\section{O autismo e a habilidade de construir narrativas}

A narração pode ser interpretada como o arranjo de uma sequência de fatos que envolvem personagens, que realizam ações com o passar do tempo. Em uma narrativa é preciso que os fatos estejam ligados por uma relação cronológica e que haja uma transformação entre a situação ou estado inicial e o final. Labov e Waletzky (1967 apud Vieira, 1997) dividem a estrutura da narrativa em cinco macropoposições: orientação ou contextualização, complicação, ação ou avaliação, resolução e conclusão ou moral.

As narrativas são fontes para diversas aprendizagens, pois, de acordo com Azeredo e Reategui (2013), contribuem para a formação do sujeito e estimulam o desenvolvimento da imaginação, da criatividade, do pensamento e afetividade. Essas aprendizagens são de grande importância na vida de pessoas autistas, porque, conforme aponta Feldman (2013), eles têm muitas dificuldades de interpretar e construir narrativas, devido a características, como por exemplo, a dificuldade de compreender algumas expressões, ironias e sentimentos, encarando a linguagem no sentido literal.

Felizmente, esses obstáculos vêm sendo alvo de pesquisadores, educadores e parentes, que se dedicam a encontrar soluções e recursos, como as chamadas tecnologias assistivas (TA), que podem ser entendidas como o conjunto de recursos, metodologias e serviços que visam promover a inclusão e melhorar a qualidade de vida das pessoas com deficiências, incapacidade ou mobilidade reduzida [Brasil, 2009].

Além das TA, há algumas ferramentas como os games permitem a vivência de diversas narrativas, em diferentes contextos e ambientes virtuais, que auxiliam os 
sujeitos a, entre outras habilidades, desenvolverem o pensamento lógico. Entretanto, Manzini (2013) refere que algumas TA requerem a formação profissional para serem utilizadas em sua plenitude, revelando a necessidade da adequação desses recursos para a realidade das escolas que, nem sempre, dispõem de espaço e de estrutura adequados.

Nessa perspectiva, é necessária certa preocupação sobre como as tecnologias digitais assistivas podem melhorar a interação entre o usuário, a interface e a máquina, assim como os possíveis efeitos dessas ferramentas na ampliação da comunicação, mobilidade e, especialmente, da aprendizagem dos autistas.

\section{Interação humano-computador e design de games}

A interação humano-computador (IHC) tem por objetivo facilitar a interação entre os recursos digitais e seus possíveis usuários [Carvalho, 2003]. Em muitas circunstâncias, as equipes de desenvolvimento de aplicativos e games, sejam eles educativos ou comerciais, foca somente sua funcionalidade e se esquecem de sua usabilidade para o usuário final, cujas experiências de uso podem ser afetadas por uma simples falta de cuidado em relação ao tamanho da fonte ou dos botões.

Este cuidado com a usabilidade também está intrinsecamente ligado ao design de games e deve ser visado desde os momentos iniciais da produção do chamado game design document (GDD), que de acordo com Schuytema (2008), é a "planta baixa" de um jogo digital e que contém toda a sua descrição estrutural e funcional.

Acredita-se que algumas das orientações propostas por Schuytema (2008) para o design de games, como: objetivos claros, regras compreensíveis, necessidade de usar habilidades lógicas, padrões não tão claros, feedback, interface coerente, bons efeitos sonoros, entre outros, podem ser de grande importância para a elaboração de um game, na perspectiva de atender às necessidades de muitos autistas, para que possam superar dificuldades, como é o caso da construção de narrativas.

\section{Trabalhos relacionados}

Visando o desenvolver o conhecimento matemático em autistas, Mello e Sganzerla (2013) apresentam uma proposta de aplicativo voltado ao Sistema Android. O texto traz algumas observações importantes sobre do design de aplicativos assistivos como, a necessidade de uma interface clara e objetiva e feedback constante ao usuário.

Teixeira, Saturnino, Lins Júnior e Cunha (2014) desenvolveram um jogo chamado HangAut, que foi criado, especialmente, para auxiliar o processo de alfabetização e estimular habilidades cognitivas de crianças autistas. As entrevistas realizadas pelos autores revelam informações importantes sobre as necessidades de um game para autistas como, por exemplo, o uso de cores sólidas e animações curtas.

Bittencourt e Fumes (2016) apresentam um relato de utilização do Sistema de Comunicação Alternativa para Letramento de Pessoas com Autismo (SCALA) em seu modo de narrativas visuais, por meio do qual o usuário pode produzir narrativas com imagens próprias do aplicativo ou, até, imagens adicionadas por ele mesmo. Diferente da proposta aqui apresentada, esse trabalho é voltado para autistas que têm uma noção da estrutura e do sequenciamento de uma narrativa, enquanto o que aqui é proposto visa desenvolvê-la, estimulando também a comunicação e a interpretação. 
VI Congresso Brasileiro de Informática na Educação (CBIE 2017)

Anais do XXVIII Simpósio Brasileiro de Informática na Educação (SBIE 2017)

\section{Metodologia}

Nesta pesquisa, foi empregada a abordagem qualitativa, de caráter exploratório e descritivo, que, para Gray (2012), caracteriza-se por ser altamente contextual e pela possibilidade de o pesquisador adotar diversas posturas e métodos, podendo mostrar através das falas e das produções como e porque os fatos acontecem.

Nos próximos itens, apresentam-se o processo de desenvolvimento, a mecânica do jogo e a metodologia empregada para aplicar o game foco desta pesquisa, que foi nomeado como Letramento Interativo para Autistas (LIA) e testado, inicialmente, com três autistas da cidade de Campina Grande - Paraíba.

O LIA é um game assistivo empregado para facilitar o desenvolvimento de habilidades de construção de narrativas em autistas, através de metodologias semelhantes a métodos interativos de ensino, como o tratamento e educação para autistas e crianças com déficits (TEACCH), abordado por Mesibov, Shea e Schopler (2004), e observações sobre o design de games e objetos educacionais assistivos como o SCALA, utilizado por Bittencourt e Fumes (2016) com foco em construir narrativas.

\subsection{Desenvolvimento}

Durante o desenvolvimento do jogo foram utilizados algumas metodologias e aspectos da área de Engenharia de Software, que envolve processo de modelagem de software, levantamento de requisitos, validação e até mesmo a utilização de metodologias ágeis. Para modelagem do game foram utilizados alguns componentes da linguagem Unified Model Language (UML) que melhor atendiam às necessidades do projeto, a exemplo do diagrama de atividade, empregado para definição de fluxos pontuais do game e que permitiu modelar partes de seu comportamento.

O diagrama de máquina de estados, componente parte do UML, permitiu representar as ideias iniciais acerca dos fluxos de telas e de jogabilidade do LIA, tornando possível materializar as ideias de possíveis fluxos, conforme a figura 1.

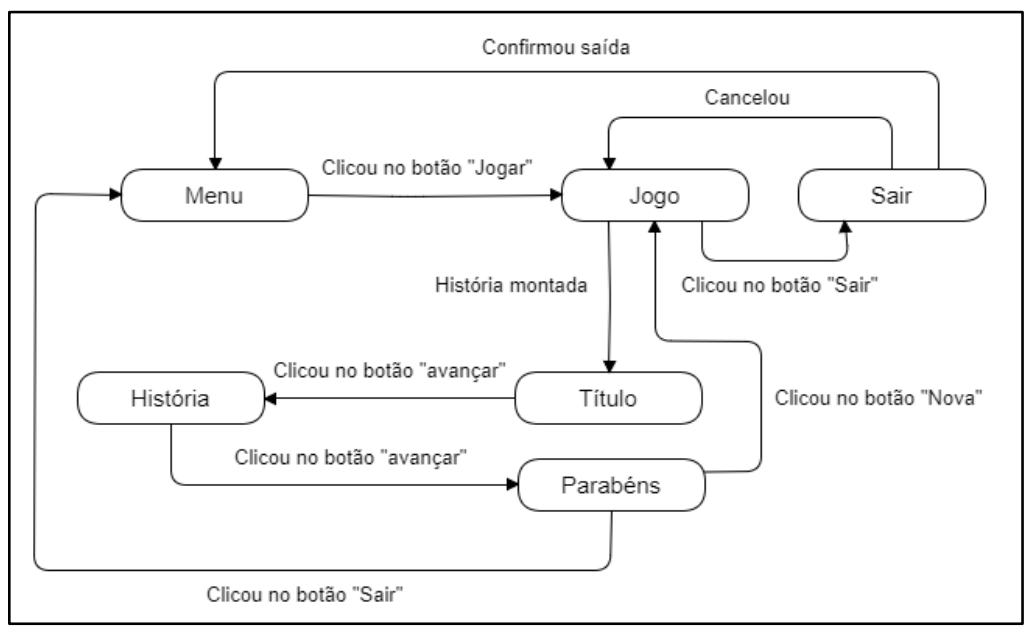

Figura 1. Fluxo de jogo do LIA

Entretanto, ao validar o modelo, devido ao fato desta proposta ser direcionada ao público autista, os estados definidos eram complexos, fazendo-se necessário a revisão do diagrama, agora, objetivando a compreensão e interação do usuário, seguindo os pressupostos da IHC e do design de games. 
Dessa forma foi elaborado uma nova versão mais simples e estruturada da seguinte forma: ao abrir o jogo, é exibido o menu principal, que contém quatro botões, o primeiro dá acesso ao jogo; o segundo, às histórias criadas pelo usuário; o terceiro, a um menu de ajuda; e o último, aos créditos. Ao clicar em "jogar", o usuário é direcionado para a tela de jogo, cujo fluxo está representado na figura 2.

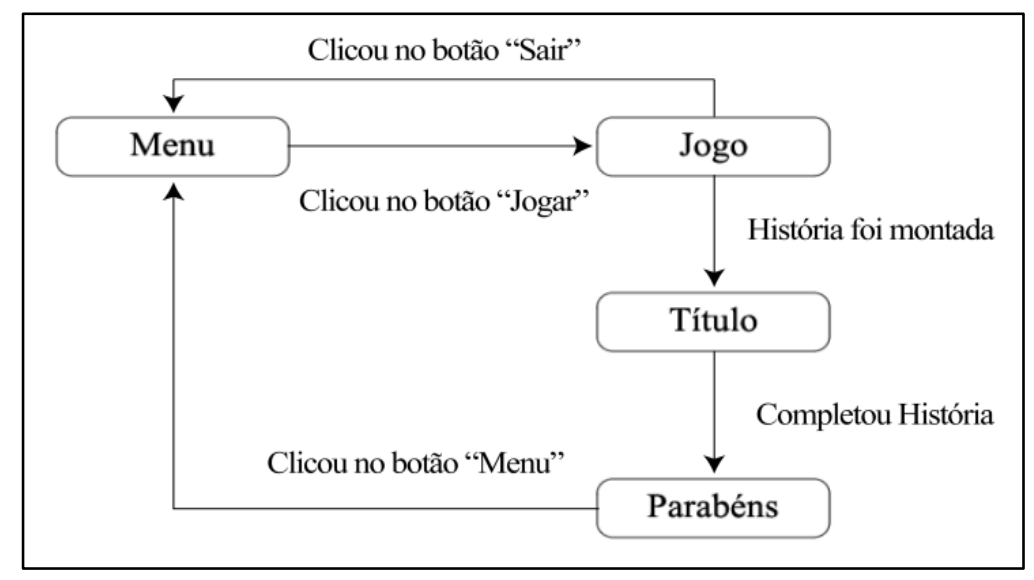

Figura 2. Fluxo de jogo do LIA

Após a validação e modelagem do LIA, foi definido para seu desenvolvimento engine Unity 3D. Este software lançado no ano de 2005 vem se destacando até os dias atuais, devido às suas inúmeras possibilidades de criar games com excelentes gráficos e mecânicas, sejam eles ambientalizados no mundo tridimensional ou bidimensional. Um bom exemplo é o jogo Ori and the Blind Forest (2015), cujos gráficos e jogabilidade envolventes conquistaram olhares de jogadores e desenvolvedores do mundo todo.

Como linguagem de programação, utilizou-se a linguagem $C \#$, linguagem fortemente tipada, declarativa, orientada a objetos e genérica, que possibilitou a modelagem de elementos do mundo real no game.

O Unity $3 D$ conta com a versatilidade de ser uma engine que suporta diversos ambientes para desenvolvimento, atendendo um dos requisitos não-funcionais do sistema, que é ter um jogo desenvolvido para plataformas móveis, em especial dispositivos com sistema operacional Android, que são utilizados com frequência por crianças de todas as idades, em especial, os autistas.

\subsection{Mecânica}

O LIA segue um fluxo de jogo contínuo e não linear, que leva o usuário a tomar decisões a cada tela, e o faz produzir suas próprias narrativas. Ao iniciar o jogo, são exibidas, três imagens, uma das quais o usuário deverá escolher e arrastar e soltar para uma parte específica da tela, chamada de campo de texto. Ao soltar a imagem sobre o campo de texto, uma frase relacionada à figura é exibida na tela.

O usuário deverá lê-la em voz alta, com o auxílio dos pais, responsáveis ou professores, e tocar em um botão para avançar para a próxima tela, onde serão exibidas novas frases e imagens. Ao arrastar e soltar uma das novas imagens no campo de texto, a frase relacionada a imagem escolhida é incrementada à anterior. Dessa forma, com o passar das telas, uma narrativa clara e objetiva é formada. 
É pertinente destacar a importância da atuação do professor, dos pais ou dos responsáveis pelo usuário na utilização dessa e de outras tecnologias digitais assistivas, pois, de acordo com Manzini (2013, p.22), "sem a ação humana, sem os processos de mediação adequados para o ensino e a aprendizagem, os recursos e os equipamentos de tecnologia assistiva, por si só, não trarão contribuição.”.

Ao fim do processo construtivo da narrativa, será exibida uma janela, com opções de títulos a serem escolhidos. Essas opções variam cada a cada jogada, e o usuário deverá escolher um deles para sua narrativa. Ao escolher esse título, será exibida a última tela de jogo, que contém toda a narrativa construída, junto do título.

Para definição das narrativas, tomou-se como base o modelo proposto por Labov e Waletzky (1967 apud Vieira, 1997), entretanto, com a elaboração de diversas frases que podem ser associadas umas com as outras sem que haja a perda do sentido e do fluxo da narração. Certamente esse é um dos maiores desafios dessa produção, porque o LIA possibilita construir mais de quatro mil narrativas diferentes, com variações de personagens, cenários, animais, desfechos, entre outras características que tornarão cada narrativa única, respeitando a pontuação, a coerência e o gênero do personagem.

Isso é possível devido à disposição das 23 frases que compõem o LIA: na primeira tela de jogo, são expostas as frases "Em um domingo de sol", "Numa manhã de chuva", "Numa tarde de férias", que combinam com "um menino chamado José" ou "uma menina chamada Bia", dispostas na segunda tela de jogo, que, por sua vez, combinam com uma destas frases: "Saiu para passear no parque com sua mãe", "Foi com a família à piscina" e "Foi a uma lojinha de animais", exibidas na terceira tela de jogo. Assim, nessas três primeiras telas, são possíveis 18 inícios diferentes para as narrativas, que crescem exponencialmente de acordo com as próximas telas do jogo.

Há, ainda, a possibilidade de escolher diferentes títulos para as narrativas, o que permite uma variação ainda maior. Cada vez em que o jogo for utilizado, serão disponibilizados aleatoriamente três dos seguintes títulos: Os amigos, Encontro inesperado, De repente amigos, Fazendo novos amigos, $\mathrm{O}$ animalzinho perdido, Amizade verdadeira e Um dia divertido. Todos eles foram escolhidos para se relacionar com as mais variadas histórias que podem ser criadas pelo usuário.

Com o objetivo de proporcionar uma boa experiência de jogo para o usuário e uma interface minimalista e funcional, o layout do LIA foi estruturado utilizando-se formas simples e poucos elementos nos menus e nas telas de jogo. Tal cuidado também está presente nas imagens desenhadas para representar cada frase e nas texturas leves utilizadas, com cores claras no fundo, conforme pode ser verificado na figura 3 .
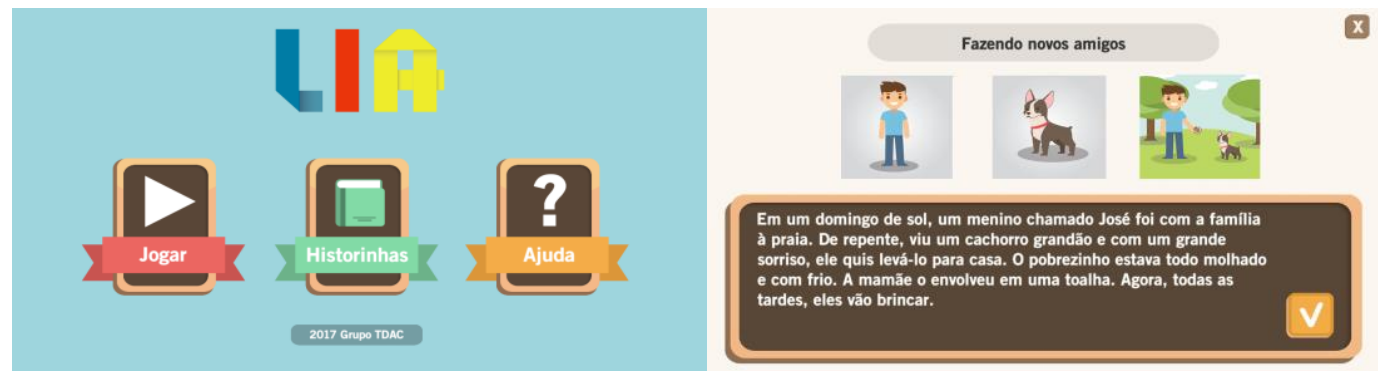

Figura 3. Tela inicial e tela de jogo do LIA 
Esses e outros cuidados, que deveriam ser inerentes ao processo de design de alguns jogos, principalmente quando educacionais, são apontados por Schuytema (2008), ao abordar os "átomos" de um game, que podem ser interpretados como suas características essenciais, que despertam o interesse e o gosto do usuário. No que diz respeito, ao LIA, é possível destacar os seguintes átomos: objetivos, regras, interface coerente e feedbacks, que influenciam, principalmente, os sujeitos autistas.

\subsection{Metodologia de aplicação}

Depois de um intenso período de testes e de discussões em laboratório, o LIA foi aplicado em sua versão beta para testes com três autistas, com faixa etária de sete a 13 anos, todos do sexo masculino. A aplicação foi feita na Associação Grupo de Mães e Pais de Autistas (GMAIS), localizada na cidade de Campina Grande, Paraíba, pelos autores desta pesquisa, entre eles, a mãe de um adolescente autista, professora de Língua Portuguesa e coordenadora pedagógica da instituição e que, com toda a sua experiência e proximidade com os sujeitos, pôde oferecer cuidados pedagógicos suficientes para o sucesso da aplicação. Esse fator foi de grande importância nesse momento e durante o planejamento do GDD do LIA.

Por uma questão de ética, os nomes dos sujeitos foram substituídos por A1, A2 e A3, preservando suas identidades. Os sujeitos apresentam os seguintes perfis: A1 tem sete anos, é alfabetizado e consegue verbalizar palavras quando são de seu interesse; A2 também tem sete anos, é alfabetizado e verbaliza palavras em tom muito baixo. Além de ser autista, tem apraxia; A3, com 13 anos, é alfabetizado, lê bem e verbaliza palavras com certa clareza.

Durante a aplicação do LIA, utilizou-se uma sala com dois cômodos - um, para o sujeito e um dos autores, e o outro, para um segundo autor, que fez observações e as anotações. O autor responsável por aplicar o LIA buscou sempre verificar a compreensão da criança e deixá-la manusear o dispositivo com o game sozinha, ou seja, fazer as próprias escolhas e executá-las.

Para verificar se os sujeitos estavam compreendendo as narrativas criadas, usouse a estratégia de uma discussão oral sobre as ações contidas no texto. Os principais questionamentos foram: "Quem é o personagem da história?", "Qual o animalzinho?", “O que o menino (a) fez com o animal?”, por meio dos quais foi possível saber se eles compreendiam ou não as situações e os momentos da estrutura de uma narrativa, conforme as macropoposições de Labov e Waletzky (1967 apud Vieira, 1997).

\section{Resultados}

A aplicação do LIA com os sujeitos A1, A2 e A3 proporcionou um momento de avaliação e validação, principalmente em seus aspectos de funcionalidade e usabilidade, através das observações, das anotações em caderno de campo e de gravações de voz. Com esses materiais, foi possível saber se características técnicas e pedagógicas do LIA, como tamanho dos objetos, interface, comandos, gráficos, animações, textos, desafios, riscos para o usuário e lógica, além de alguns aspectos do design de games abordados por Schuytema (2008) atendem às necessidades e às dificuldades dos autistas.

Durante os momentos de aplicação, os sujeitos da pesquisa demonstraram que tinham muita intimidade com o artefato digital e sua interface e não tiveram dificuldade de manuseá-lo e de interagir com ele, fato presente nos escritos de Moita (2007), 
VI Congresso Brasileiro de Informática na Educação (CBIE 2017)

Anais do XXVIII Simpósio Brasileiro de Informática na Educação (SBIE 2017)

quando assevera que as crianças, os jovens e os adultos que nasceram e vivem em um mundo cercado pelas TDIC apresentam diferentes formas de agir, de interagir, de se comunicar e de aprender e estão intimamente ligados e habituados a usá-la.

A aplicação revelou também que, apesar de apresentarem as características relacionadas ao autismo, os sujeitos A1, A2 e A3 tinham perfis e gostos diferentes, e cada um produziu, sem dificuldades, através do LIA, uma narrativa distinta e de acordo com suas preferências, como descrito no quadro 1.

Quadro 1. Narrativas criadas pelos sujeitos A1, A2 e A3

\begin{tabular}{|c|c|l|}
\hline $\begin{array}{c}\text { Sujeit } \\
\text { o }\end{array}$ & Título & \multicolumn{1}{c|}{ Narrativa } \\
\hline A1 & $\begin{array}{c}\text { Fazendo } \\
\text { novos amigos }\end{array}$ & $\begin{array}{l}\text { Em um domingo de sol, um menino chamado José foi a uma lojinha de } \\
\text { animais. Quando percebeu um lindo coelho branco e ficaram logo } \\
\text { amigos. Ele era muito fofinho. A criança quis levá-lo para casa. Então o } \\
\text { bichinho ficou muito feliz e foi com ele para casa. }\end{array}$ \\
\hline A2 & Os amigos & $\begin{array}{l}\text { Em uma tarde de férias, uma menina chamada Bia foi com a família à } \\
\text { praia. Quando percebeu um lindo coelho branco e deu um grande abraço } \\
\text { no animal. O pobrezinho estava todo molhado e com frio. A mãe } \\
\text { comprou comida para os dois. Agora, todas as tardes, eles vão brincar. }\end{array}$ \\
\hline A3 & $\begin{array}{c}\text { Amizade } \\
\text { verdadeira }\end{array}$ & $\begin{array}{l}\text { Em um domingo de sol, um menino chamado José foi a uma lojinha de } \\
\text { animais. Lá ele viu um gato bem peludo e com um grande sorriso, ele } \\
\text { quis levá-lo para casa. Ele era muito fofinho. A mãe comprou comida } \\
\text { para os dois. Agora, todas as tardes, eles vão brincar. }\end{array}$ \\
\hline
\end{tabular}

Por meio desses dados, é possível notar o caráter minimalista e funcional do LIA, além de suas diferentes possibilidades de criar narrativas, o que era uma preocupação por parte da equipe, uma vez que os usuários poderiam, por exemplo, optar por selecionar sempre as primeiras imagens em todas as telas, sem entender o seu real significado ou o objetivo do LIA.

Vale ressaltar a importância da atuação de algum professor, pai ou parente que busque sempre fazer questionamentos e manter diálogos com o autista, para que dificuldades como a de interpretar e a de produzir narrativas com lógica sejam superadas [Feldman, 2013]. Também foi observada a função de estímulo ao desenvolvimento da linguagem e à comunicação do autista proporcionada pelo LIA, na medida em que é conduzido a verbalizar as frases com o auxílio do pai, do responsável ou do professor.

Por fim, com os registros obtidos, ficaram claros os ajustes necessários ao LIA, que serão de grande importância nos próximos passos de seu desenvolvimento e de sua validação. Entre eles, está a necessidade de certo tempo de espera antes de o botão de avanço de tela ser exibido, a fim de que o autista tenha tempo de ler a frase formada, pois notamos, com todos os sujeitos, que o botão estava causando certa curiosidade ou ansiedade de avançar para as próximas telas.

Outro aspecto que deve ser observado diz respeito ao tamanho texto e das imagens na tela de jogo, principalmente do texto, uma vez que o público-alvo do LIA são crianças que muitas vezes se encontram em processo de alfabetização, facilitando a leitura. $\mathrm{O}$ aumento do texto também deriva da necessidade de chamar-se mais atenção da escrita do que das imagens, que não podem ser muito pequenas também, evitando-se dificuldades visuais e também a exaustão. 
Estas necessidades foram observada em todos sujeitos e isso se justifica pelo fato de os autistas serem "pensadores visuais" ou "visual thinkers", conforme aponta Grandin (1995) e Sacks (1995, apud RIBEIRO, 2003). Isso significa que eles processam o pensamento em imagens, portanto, precisam de ambientes claros, bem visíveis e organizados para aprender.

Depois de feita essa aplicação, pretende-se proceder às correções observadas e adicionar novos recursos ao game, como a possibilidade de criar contas para cada usuário e de gravar as histórias já criadas, com sincronização via internet para um servidor, de modo que a equipe desenvolvedora tenha acesso a informações, como por exemplo, as opções mais selecionadas pelos usuários. Também se pretende reproduzir as frases formadas com voz humana pelo aplicativo, para que possa auxiliar na pronúncia e estimular os autistas a se comunicarem cada vez mais verbalmente.

\section{Conclusões}

Com o objetivo de apresentar o processo de design, desenvolvimento e de validação de um game assistivo, com foco na construção de narrativas para autistas, este artigo trouxe importantes observações a respeito de alguns cuidados técnicos e pedagógicos, fundamentados em estudos sobre a IHC, o design de games e as tecnologias assistivas, que podem impactar a experiência de uso e a aprendizagem de crianças e jovens autistas com os mais variados perfis.

Denominado de LIA, o game desenvolvido apresenta grande facilidade de acesso e de utilização, evidenciada nos resultados positivos que foram obtidos em sua validação. Entre eles, destacam-se a atratividade e a compreensão dos sujeitos a respeito dos objetivos e do funcionamento do game e sua função de estimular o desenvolvimento da fala e da interação.

Como o espectro do autismo é muito amplo, e essa testagem só envolveu três sujeitos, são necessários novos testes com um número maior de autistas para solidificar as conclusões a respeito da função pedagógica do game. Além disso, com as observações realizadas, será possível desenvolver outras versões do LIA, com aprimoramentos e recursos adicionais que, certamente, contribuirão com seu sucesso como ferramenta facilitadora do processo de construção de narrativas com autistas.

\section{Referências}

Azeredo, D. C., \& reategui, E. (2013). A construção de narrativas digitais como apoio ao processo de letramento. Novas Tecnologias na Educação, Porto Alegre. 11(1).

Barbosa, S., \& Silva, B. (2010), Interação humano-computador. Rio de Janeiro: Campus-Elsevier.

Bittencourt, I., \& Fumes, N. (2016, Novembro). A tecnologia assistiva SCALA na promoção de narrativas de sujeitos com transtorno do espectro autista sobre as suas experiências escolares e o autismo. Em Simpósio Brasileiro de Informática na Educação-SBIE, 27 (1), 767-776.

Brasil. Subsecretaria Nacional de Promoção dos Direitos da Pessoa com Deficiência. Comitê de Ajudas Técnicas (2009), Tecnologia Assistiva - Brasília: CORDE, 2009. 
VI Congresso Brasileiro de Informática na Educação (CBIE 2017)

Anais do XXVIII Simpósio Brasileiro de Informática na Educação (SBIE 2017)

Carvalho, J. O. F. (2003). O papel da interação humano-computador na inclusão digital. Transinformação (15),75-89. http://dx.doi.org/10.1590/S0103-37862003000500004.

Feldman, C., Costa, J. S. F., Júnior, O. D. d. S., Ortega, F. J. G., Lima, R. C., \& Zorzanelli, R. T. (2013). Relatos sobre autismo: um estudo sobre narrativas em primeira pessoa. Universidade do Estado do Rio de Janeiro.

Gee, J. P. (2010), Bons videojogos + boa aprendizagem: coletânea de ensaios sobre os videojogos, a aprendizagem e a literacia. Mangualde, Ramada: Edições Pedago.

Grandin, T. (1995), Thinking in pictures. New York: Doubleday.

Gray, D. E. (2016), Pesquisa no mundo real. Penso Editora.

Manzini, E. J. (2013). Formação do professor para o uso de tecnologia assistiva. Cadernos de Pesquisa em Educação PPGE-UFES, 18, 11-36.

Mello, C. M. C., \& Sganzerla, M. A. R. (2013, outubro). Proposta de aplicativo android para auxiliar no desenvolvimento matemático de pessoas com autismo. Anais do VI CIEM, Canoas, RS, Brasil.

Mesibov,G. B., Shea, V., \& Schopler, E. (2004). The Teacch Approach to Autism Spectrum Disorders. New York, NY: Springer Science + Business Media.

Moita, F. M. S. C. (2007), Game On: jogos eletrônicos na escola e na vida da geração @. Alínea.

Prensky, M. (2001), Nativos digitais, imigrantes digitais. NCB University Press.

Ribeiro, V. L.B. Breve análise da cognição da pessoa com autismo. Disponível em: < http://topicosemautismoeinclusao.blogspot.com. Acessado em 22 de jun. 2017.

Schuytema, P. (2008), Design de games - uma abordagem prática. Cengage Learning.

Studios, M. (2015). Ori and the blind forest. Disponível em: https://www.orithegame.com/

Teixeira, J.; Ximenes, M.; Barbosa, P., \& Lima, R. (2014, novembro). FORCAUT GAME: um jogo mobile para apoiar um processo de alfabetização de crianças com autismo. Anais do Congresso Brasileiro de Educação Especial, Campinas, SP, Brasil. doi: http://dx.doi.org/10.17648/galoa-cbee-6-29414.

Vieira, A. G. (1997). O brinquedo simbólico como uma narrativa. Dissertação de Mestrado, Porto Alegre, Rio Grande do Sul, Brasil. Disponível em: http://www.lume.ufrgs.br/handle/10183/1478. 